Urol. Prax. 2021 $23: 94$

https://doi.org/10.1007/s41973-021-00133-2

Publié en ligne: 24. Mars 2021

(c) Springer-Verlag GmbH Austria, ein Teil von Springer Nature 2021

Hubert John ${ }^{1} \cdot$ Anja Sauck ${ }^{1}$ Ladislav Prikler ${ }^{2}$

'Clinique d'urologie, EBU Certified Training Centre, hôpital cantonal de Winterthour, Winterthour, Suisse

${ }^{2}$ Gesellschaft der Urologen des Kantons Zürich, Bülach, Suisse

\section{Erratum à: Éditorial}

Erratum à:

Urol. Prax. 2021

https://doi.org/10.1007/s41973-021-

00132-3

Chers lecteurs,

dans la publication originale de cet article, le 05 février 2021, il y a malheureusement eu une erreur.

Les portraits d'Anja Sauck, MD, et de Ladislav Prikler, MD, ont été échangés.

Nous vous demandons de bien vouloir prendre note de la correction et de nous excuser pour l'erreur.

\section{Adresse de correspondance}

Prof. Dr. med. Hubert John
Clinique d'urologie, EBU
Certified Training Centre,
hôpital cantonal de
Winterthour
8401 Winterthour, Suisse
hubert.john@ksw.ch

La version en ligne de l'article original peut être consultée à l'adresse https://doi.org/10.1007/ s41973-021-00132-3. 